\title{
Developmental and age-related changes to the elastic lamina of Bruch's membrane in mice
}

\author{
Hidetsugu Mori ${ }^{1}$ (D) Haruhiko Yamada ${ }^{1} \cdot$ Keiko Toyama $^{1} \cdot$ Kanji Takahashi $^{1} \cdot$ Tomoya Akama $^{2} \cdot$ Tadashi Inoue $^{2}$. \\ Tomoyuki Nakamura ${ }^{2}$
}

Received: 15 May 2018 / Revised: 10 October 2018 / Accepted: 9 November 2018 / Published online: 29 November 2018

(C) The Author(s) 2018

\begin{abstract}
Background Fibrillin-1, tropoelastin, fibulin-5, and latent transforming growth factor beta-binding protein-2 and protein-4 (LTBP-2 and LTBP-4) are essential proteins for the elastic lamina (EL). In this study, we analyzed each of these molecules in the EL of Bruch's membrane (BM) through development and aging.

Methods C57BL/6 mice (embryonic (E) days E12.5, E15.5, and E18.5; postnatal (P) days P1, P4, and P7 and P3, P6, and P75 weeks of age) were used. To investigate localization, immunohistochemical staining (IH) was performed. Transmission electron microscopy (TEM) was used to evaluate the formation of microfibrils and tropoelastin. mRNA expression was determined by quantitative real-time PCR (qRT-PCR).

Results All five proteins were expressed in the EL of BM by IH except in embryonic mice. TEM results showed that tropoelastin co-stained with microfibrils. Between 3 and 6 weeks of age, microfibrils became longer and thicker. It was difficult to evaluate the EL of BM in senile mice at 75 weeks of age because of abundant deposits which correspond to drusen. mRNA levels of each protein increased dramatically from E15.5 to P1 days and plateaued by P3 weeks as shown by qRT-PCR.

Conclusions In conclusion, these five proteins are possibly involved in elastic fiber assembly in BM. We define the date of full assembly of the EL of BM as 3 weeks of age in mice.
\end{abstract}

Keywords Elastic lamina of Bruch's membrane · fibrillin1 · Fibulin-5 · Tropoelastin · LTBP-2 · LTBP-4

\section{Introduction}

Bruch's membrane (BM) has a thin and complex structure with five stratified layers that contain the basement membrane of the retinal pigment epithelium (RPE), the inner collagenous layer, the central elastic layer, the outer collagenous layer, and the basement membrane of the choriocapillaris endothelium (CCE) [1, 2]. Bruch's membrane plays a critical role in the eye. Transport of oxygen, glucose, growth factors, and fluids derived from choroidal vasculature to the retina/RPE and removal of waste

Hidetsugu Mori

morih@hirakata.kmu.ac.jp

1 Department of Ophthalmology, Kansai Medical University, 2-5-1 Shinmachi, Hirakata, Osaka 573-1191, Japan

2 Department of Pharmacology, Kansai Medical University, Osaka, Japan materials from the RPE through BM supports the function and health of RPE and photoreceptors [3-5]. Bruch's membrane also works as a tight barrier to prevent abnormal angiogenesis $[6,7]$ as the rupture of BM may induce choroidal neovascularization $(\mathrm{CNV})$ [8-15]. Therefore, maintaining the five-layer structure of BM is essential for retinal health and normal visual function. Particularly, damage of elastic lamina and/or mutations in the genes encoding elastic fibers in BM is associated with severe vision loss by $\mathrm{CNV}$ formation according to previous studies $[6,15,16]$. Chong et al. reported that discontinuities within the elastic lamina of BM are significantly longer in patients with agerelated macular degeneration (AMD) than in age-matched controls [6]. Sivaprasad et al. reported that serum levels of elastin-derived peptides in patients with AMD are significantly higher than that in non-AMD patients [16]. Jones et al. reported that mouse RPE overexpression of human high temperature requirement A 1 (HTRA1) induced polypoidal choroidal vasculopathy (PCV) which is a subtype of AMD [15]. The degeneration of the elastic lamina 
of BM induced by human HTRA1 as a multifunctional serine protease that works as elastase activity $[17,18]$ was the major factor for the occurrence of PCV.

Discontinuities of the elastic lamina of BM may be predictors for the occurrence of CNVs [6]. Among the five layers in $\mathrm{BM}$, proper homeostasis and turnover of the elastic lamina of $\mathrm{BM}$ seems to be essential to prevent CNV. Therefore, it is important to improve understanding of the elastic lamina of $\mathrm{BM}$ in terms of histology and molecular biology characteristics.

Elastic fibers give connective tissue resilience, deformability, and recoil abilities without energy input [19,20]. Elastic fibers play the principal role in the structural integrity and function of various organs [20]. Knowledge in the field of elastic fiber assembly-related molecules has spread in recent years owing to the identification of gene mapping of elastic fibers using in vivo studies (transgenic mouse models) and in vitro studies (biochemical examinations) [19-48]. Elastic fibers are composed of two major composite biomaterials including an outer lattice of microfibrillar mantle mainly consisting of polymers of fibrillin-1 and an inner amorphous core of crossed-linking tropoelastin (elastin monomers) [20-22]. Several molecules associated with the coacervation and cross-linking between microfibrils and tropoelastin have been implicated in the process of elastic fiber assembly. Recent genetic studies have revealed that fibulin- 5 , latent transforming growth factor- $\beta$-binding protein-2 (LTBP-2), and LTBP-4 are involved in elastic fiber assembly in addition to microfibrils and tropoelastin $[34,38]$. Schematic view of elastic fiber assembly involves recruitment and organized deposition of molecules including fibrillin-1, tropoelastin, fibulin-5, LTBP-2, and LTBP-4, as shown in Fig. 1. The complete molecular mechanism in elastic fiber assembly remains unclear. Structural components of these five molecules (fibrillin-1, fibulin-5, tropoelastin, LTBP-2, and LTBP-4) differ between organs. For example, ciliary zonules consist of rich microfibrils and LTBP-2 only [34]. There have been no reports about whether these five molecules are expressed in the elastic lamina of BM. Researching the elastic lamina of BM may lead to elucidating the mechanism of $\mathrm{CNV}$ development.

In this study, we analyzed the relationships between these five molecules and the elastic lamina of BM through prenatal and postnatal development and in aging by both qualitative and quantitative assessments using wild-type mice.

\section{Materials and methods}

\section{Animals}

In the following descriptions, the day or week of embryonic or postnatal development were used (e.g., E15 to designate the 15th day after fertilization, P6 weeks to indicate the 6th week after birth). In this study, male and female C57BL/6 mice (each E12.5, E15.5, and E18.5 days; P1, P4, and P7 days; and P3, P6, and P75 weeks of age) were purchased from CLEA Japan (Tokyo, Japan). All animal experiments were carried out in accordance with the ARVO Statement for the Use of Animals in Ophthalmic and Vision Research and the Guideline for Animal Experimentation at Kansai Medical University. Major ocular structures appear and are able to be differentiated between E10 and E15 days [49]. Therefore, fetal mice were studied starting at E12.5 days in this study. Animals were housed with a normal laboratory diet in a temperature and humidity-controlled environment at $22{ }^{\circ} \mathrm{C}$ and $50 \%$ filtered air. All mice were kept in pathogen-free plastic cages with 12-h light-dark cycles and had continuous free access to water and food (CLEA Japan, Tokyo, Japan). All plastic cages, water and bedding feed were purified before use.

Sixteen eyes of eight mice per time point were used for each examination: immunohistochemistry, transmission electron microscopy (TEM), and quantitative real-time polymerase chain reaction (qRT-PCR).

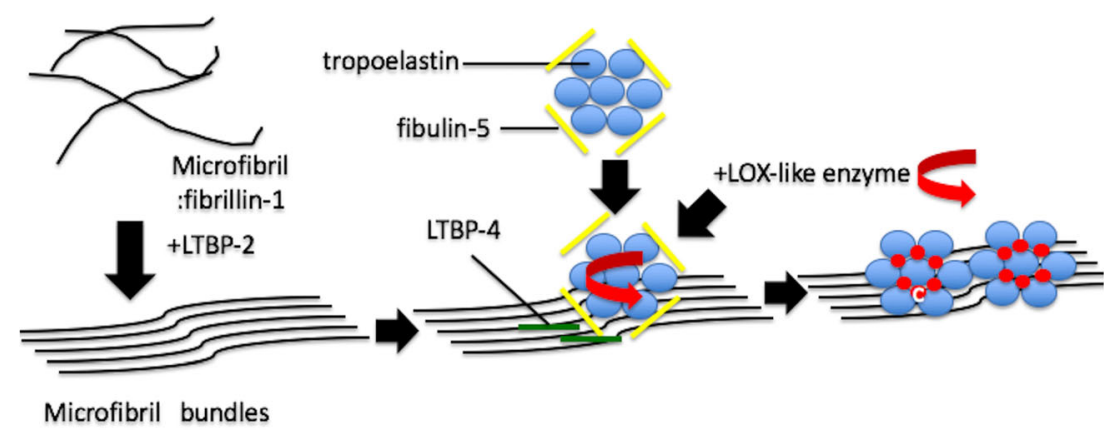

Fig. 1 Roles of elastogenic molecules in elastic fiber assembly. LTBP-2 leads each microfibril to the formation of a microfibril bundle. The coacervation of tropoelastin is carried out by fibulin-5. A cluster of tropoelastin and fibulin-5 is deposited onto microfibril bundles by

LTBP-4, which is localized on microfibrils. Then, LOX-like enzyme forms a cross-linked structure made up of the tropoelastin/fibulin-5 complex on microfibrils, which marks the completion of the elastic fiber assembly 
We defined the embryonic period as three stages: early (E12.5 days), middle (E15.5 days), and late (E18.5 days).

\section{Immunohistochemistry}

All mice were killed by cervical dislocation after deep intraperitoneal injection of a mixture containing $7 \mu \mathrm{l} / \mathrm{mg}$ of ketamine hydrochloride (Daiichisankyo, Tokyo, Japan) and $0.7 \mu \mathrm{l} / \mathrm{mg}$ of xylazine (Bayer, Leverkusen, Germany). The eyes were enucleated immediately and frozen using dry ice, followed by embedding in optimal cutting temperature compound (Tissue-Tek OCT; Sakura Finetek, Torrance, CA, USA). The frozen blocks were preserved overnight at $80^{\circ} \mathrm{C}$. Vertical and $8 \mu \mathrm{m}$ thin-sliced sections were cut with a cryostat (Leica CM3050S®; Leica Biosystems, Nußloch, Germany). To minimize tissue damage during dissection, Kawamoto's films (SECTION-LAB, Hiroshima, Japan) were used [50]. Each section with Kawamoto's film was air dried at room temperature for $20 \mathrm{~min}$. Immunohistochemistry was performed by the indirect immunofluorescence technique. Briefly, cryostat sections were fixed with cold methanol at $20^{\circ} \mathrm{C}$ for $5 \mathrm{~min}$, washed with phosphate-buffered saline (PBS) for $5 \mathrm{~min}$, and blocked with $4 \%$ blocking agent prepared from lactoprotein (Sumitomo Dainippon Pharma, Osaka, Japan) for $20 \mathrm{~min}$. The sections were then incubated with the primary antibodies anti-fibrillin-1 (1:100, original), mouse polyclonal anti-tropoelastin (1:100, Elastin Products Company), rabbit polyclonal anti-fibulin-5 (1:100, BSYN2473), anti-LTBP-2 (1:100, original) and goat polyclonal anti-LTBP-4 (1:100, R\&D Systems) for $1 \mathrm{~h}$ at room temperature. After incubation, these sections were rinsed with PBS, and then incubated with a combination of Alexa Fluor®-488, Alexa Fluor®-546 (1:200, Thermo Fisher Scientific, Waltham, MA, USA), and DyLight@-650 (1:200, Leinco technologies, Fenton, MO, USA) secondary antibodies for $1 \mathrm{~h}$ at room temperature. The combinations of primary antibodies and secondary antibodies are shown in Table 1. After rinsing with PBS, the sections were mounted with ProLong®Gold mounting media

Table 1 All primary and secondary antibodies used in this study for immunohistochemistry

\begin{tabular}{ll}
\hline Primary antibody & Secondary antibody \\
\hline Fibrillin-1, tropoelastin, fibulin-5 & Anti-rabbit Alexa Fluor® 488 \\
LTBP-4 & Anti-goat Alexa Fluor® 546 \\
LTBP-2 & Anti-chicken DyLight@ 650 \\
\hline
\end{tabular}

Anti-fibrillin-1, tropoelastin, and fibulin-5 primary antibodies were stained with Alexa Fluor ${ }^{8} 488$ as the secondary antibody. Anti-LTBP-4 primary antibody was stained with Alexa Fluor ${ }^{8} 546$ as the secondary antibody. Anti-LTBP-2 primary antibody was stained with Alexa Fluor $^{8} 650$ as the secondary antibody
(Thermo Fisher Scientific, Waltham, MA, USA) for preventing fluorescence photobleaching. The sections were observed and images were taken with a fluorescence microscope (BZ-X700®; KEYENCE, Osaka, Japan). Negative control slides were stained by primary non-specific IgG (anti-goat, 144-09531; anti-rabbit, 148-09551) and/or IgY (antichicken, PSC-3707-1) antibodies one at a time to confirm positive staining of immunohistochemistry.

Triple staining with the immunofluorescent technique was performed; fibrillin-1 (Alexa Fluor®-488)-LTBP-4 (Alexa Fluor®-488)-LTBP-2 (DyLight $\left.{ }^{\circledR}-650\right)$, tropoelastin (Alexa Fluor®-488)-LTBP-4 (Alexa Fluor®-488)-LTBP-2 (DyLight@-650), fibulin-5 (Alexa Fluor®-488)-LTBP-4 (Alexa Fluor®-488)-LTBP-2 (DyLight@-650).

\section{TEM}

After deep intraperitoneal injection as described above, all mice were killed and pre-fixed with perfusion fixation from the heart by $2 \%$ glutaraldehyde (Electron Microscopy Sciences, Hatfield, PA, USA), $1 \mathrm{mM} \mathrm{CaCl}_{2}$ in $0.1 \mathrm{M}$ sodium cacodylate (Electron Microscopy Sciences, Hatfield, PA, USA), and 1/15 $\mathrm{M}$ phosphate buffer without $\mathrm{NaCl}$ ( $\mathrm{pH} 7.4$ ). Immediately afterwards, each eye was enucleated. We dissected the eyes carefully under a microscope at the corneal limbus and removed the lens. Posterior eyecups were immersed in fixation liquid of $2 \%$ glutaraldehyde and $1 \mathrm{mM} \mathrm{CaCl} 2$ in $0.1 \mathrm{M}$ sodium cacodylate buffer ( $\mathrm{pH} 7.4$ ) and preserved at $4{ }^{\circ} \mathrm{C}$ for $2 \mathrm{~h}$. After pre-fixation, samples were washed twice by $0.2 \mathrm{M}$ sucrose in $0.1 \mathrm{M}$ sodium cacodylate buffer $(\mathrm{pH} 7.4)$ for $10 \mathrm{~min}$. Posterior eyecups were postfixed for $2 \mathrm{~h}$ in $1 \%$ osmium tetroxide (Nissin EM, Tokyo, Japan) and $0.15 \mathrm{M}$ sodium cacodylate buffer at $4{ }^{\circ} \mathrm{C}$, dehydrated through a series of subsequent high-grade ethanol concentrations, and embedded in epoxy resin (TAAB Laboratories Equipment Ltd., Aldermaston, Berks, England). Semi-thin sections (1 $\mu \mathrm{m}$ thick) were cut with an ultramicrotome (REICHERT-NISSEI ULTRACUT S®; Leica AG, Wien, Austria). These semi-thin sections were stained with toluidine blue for identifying BM under a light microscope. Then, ultrathin sections were cut at $50 \mathrm{~nm}$ by an ultramicrotome with diamond knives (Diatome AG, Biel, Switzerland) and mounted on 100 mesh copper grids (Veco B.V., Karel van Gelreweg, Eerbeek, The Netherland). These sections were stained with uranyl acetate (Cerac, Inc., Milwaukee, WI, USA) for $10 \mathrm{~min}$ and with lead citrate (TAAB Laboratories Equipment Ltd., Aldermaston, Berks, England) for $5 \mathrm{~min}$. Then these sections were stained with tannic acid (Nacalai Tesque, Kyoto, Japan) and $p$-nitrophenol (Wako, Osaka, Japan) for $1 \mathrm{~h}$ to facilitate the visualization of tropoelastin as small black dot-like deposits. Electron micrographs of BM were viewed and taken with 80 kV under TEM (JEM-1400A®; JEOL, Tokyo, Japan). 


\section{qRT-PCR}

All mice were killed by cervical dislocation after deep intraperitoneal injection as described above. Immediately, after each whole eye was enucleated, they were stored in RNAlater® (Thermo Fisher Scientific, Waltham, MA, USA) and homogenized by Biomasher (Nippi Inc., Tokyo, Japan). Total RNA was isolated using RNeasy Plus Micro® and Mini ${ }^{\circledR}$ Kit (Qiagen, Venlo, The Netherlands) according to the manufacturer's protocol. Total RNAs were reversetranscribed to generate single-stranded complementary DNA (cDNA) using the SuperScript ${ }^{\circledR}$ VILO ${ }^{\text {TM }}$ cDNA Synthesis Kit (Thermo Fisher Scientific, Waltham, MA, USA). The reverse-transcriptase cDNAs were then subjected to qRTPCR (Thermal Cycler Dice ${ }^{\circledR}$ Real Time System II; TAKARA Bio, Otsu, Shiga, Japan). Each qRT-PCR was performed in a $20-\mu l$ volume using the SYBR ${ }^{\circledR}$ Premix Ex TaqII ${ }^{\mathrm{TM}}$ PCR Kit (TAKARA Bio, Otsu, Shiga, Japan) protocol as follows: pre-denaturing at $95^{\circ} \mathrm{C}$ for $30 \mathrm{~s}, 5$-s denaturing at $95{ }^{\circ} \mathrm{C}$, and 30-s annealing and extending each at $60{ }^{\circ} \mathrm{C}$. Denaturing, annealing, and extending were repeated for 40 cycles.

Targeting sequences used in this study were amplified with the following primers.

Fibrillin-1:

- Forward, 5'-AATATCTCGGAGCCATTTGC-3'

- Reverse, 5'-CAGGTCTACGGCAGTTGTCA-3'

Tropoelastin:

- Forward, 5'-CTATGGAGGACCCCTTGGAG-3'

- Reverse, 5'-CACAGGATTTCCCAAAGCAG-3'

Fibulin-5:

- Forward, 5'-CCGATACCCTGGTGCCTATT-3'

- Reverse, 5'-GCACTGATAGGCCCTGTTTG-3'

LTBP-2:

- Forward, 5'-AAACCCCTCAGCGACCCGCGGCTGC-3'

- Reverse, 5'-TGCTTCTGTGAGGACCGGGTGCTCT-3'

LTBP-4:

- Forward, 5'-GCACAAATACTAAAGGCTCCTTCCAC-3'

- Reverse, 5'-GACACTCGTCAATGTCAAGGCAGGAG-3'

Cyclophilin:

- Forward, 5'-CAGACGCCACTGTCGCTTT-3'

- Reverse, 5'-TGTCTTTGCAACTTTGTCTGCAA-3'
Quantitative mRNA expression levels in each age group were normalized to the amount of cyclophilin mRNA as an internal control. Quantitative mRNA expression levels in each age group were calculated by relative quantification (standard curve method). We used the mRNA of the whole eye at P12 weeks as a standard sample. Quantitative mRNA expression levels in eye tissues was calculated with logarithmic transformation and analyzed by JMP software (SAS institute, Inc., Cary, NC, USA). All data were presented as mean \pm SD according to normal distribution by Bartlett's test. Statistical analyses were performed by Tukey-Kramer test. $P$ values < 0.05 were considered statistically significant.

\section{Results}

\section{Immunohistochemistry}

Bruch's membrane was observed as the gap between RPE pigment and the choroid layer under bright-field light microscope (Fig. 2a). At embryonic stages, BM could not be detected clearly under the light microscope because BM was too faint and fragile (Fig. 2b). The BM gap was not obvious in the developing mouse at the embryonic early stage (Fig. 2b, left). However, this gap became visible from the embryonic middle stage and onwards (Fig. 2b, center and right).

At embryonic early and middle stages, staining of the five proteins (fibrillin-1, tropoelastin, fibulin-5, LTBP-2, LTBP-4) was not detected in BM (data not shown). However, fibrillin-1 showed a strong staining signal in the sclera at the embryonic early stage (data not shown). Tropoelastin, fibulin-5, LTBP-2, and LTBP-4 showed a strong staining signal in the sclera at the embryonic middle stage (data not shown). At the embryonic late stage, positive staining of fibrillin-1 and LTBP-4 in BM was isolated and weak (data not shown), but tropoelastin, fibulin-5, and LTBP-2 were positive in BM in some slides. Immunohistochemical staining confirmed the consistent expression of all five matrix proteins in BM except in embryonic stages, which indicated that production and/or deposition of the matrix proteins were dramatically enhanced at $\mathrm{P} 1$ days and onwards (Fig. 3). A summary of immunohistochemical staining in BM in each age group is shown in Fig. 4.

We further analyzed the localization pattern of each protein in BM. Figure 5 represents a summary of the characteristic staining pattern of each protein. Fibrillin-1 was detected as linear continuous long lines at postnatal stages (Fig. 5a). Tropoelastin was confirmed as a dot-like pattern at postnatal stages (Fig. 5b). LTBP-2 and LTBP-4 were co-localized with fibrillin-1 (Fig. 5c). Moreover, there was co-localization between tropoelastin and LTBP-2 by merged images (Fig. 5d). There was no clear difference in staining intensity among these five proteins with regard to exposing time, fluorescence intensity, or location (peripheral or center regions). 

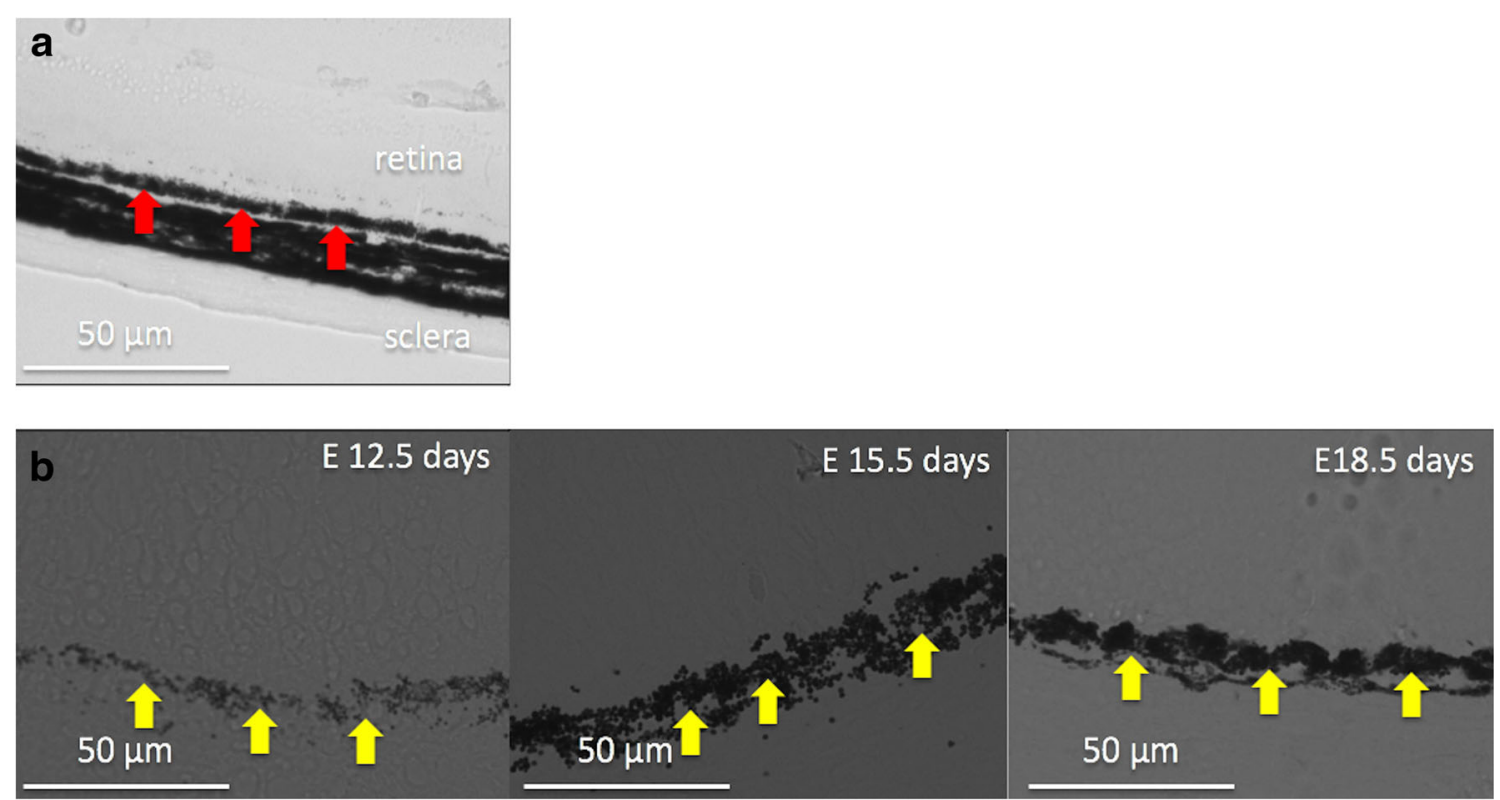

Fig. 2 Light microscopic appearance of Bruch's membrane during development. a Bruch's membrane of C57/BL6 mice is observed as the white layer between the retinal pigment epithelium and the choroid under a bright-field microscope (red arrow). b Three bright-field images show embryonic early (E12.5 days), middle (E15.5 days), and late (E18.5 days) stages. A clear white layer confirms that Bruch's membrane is fully assembled by the embryonic late stage. All images were taken at $\times 400$ magnification

\section{TEM}

At the embryonic early stage (E12.5 days), BM was mostly observed as an empty space between the RPE and CCE. Single layer as the basement membrane of RPE was lined along with RPE. Short and small clusters of fibrous microfibrils were detected. Tropoelastin occasionally overlapped with clusters of microfibrils (Fig. 6a). At the embryonic middle stage (E15.5 days), another single layer inside of the basement membrane of CCE appeared parallel to CCE. Two layers of collagenous fibrils were observed in the space between the basement membrane of the RPE and elastic fibers. The basement membrane of the RPE was lined along with the CCE. Clusters of microfibrils connected by tropoelastin gradually began to accumulate in the middle layer of BM (Fig. 6b). At the embryonic late stage (E18.5 days), short and small clusters of immature elastic fibers began to increase and connect to each other. Two collagenous fibrils began to form a threedimensional meshwork-like helix structure (Fig. 6c). At P1 day, extended microfibrils attached by tropoelastin grew and connected to form as cross-linked structure in BM (Fig. 6d). From P4 to P7 days, microfibrils with tropoelastin became thick central bundles, indicating that it became a layer of relatively uniform structure (Fig. 6e, f). From P3 to P6 weeks, a mostly consecutive single structure of microfibrils attached by tropoelastin became longer and thicker (Fig. 6g, h). Two collagenous layers became thick and formed a tight meshwork. Bruch's membrane was able to be identified as five discrete layers during P3 to P6 weeks. Their morphology indicated that developmental formation of BM was completed from P3 to P6 weeks. The elastic lamina of BM could not be clearly identified at P75 weeks because abundant dense deposits in BM localized to the RPE and disturbed the ability to distinguish the structure of BM (Fig. 6i).

The elastic lamina of BM presented discontinuity from embryo to senile stages in this study. Furthermore, the thickness of BM varied in location (Fig. 7).

\section{qRT-PCR}

\section{Fibrillin-1 mRNA}

The mean mRNA level of fibrillin-1 (Fig. 8a) at E12.5 days was low $(926.3 \pm 249.1)$. Significant elevation of mRNA levels were observed at E15.5 days $(13,954.4 \pm 4371.5)$ compared with those of other time points $(P<0.01)$. mRNA expression levels were maintained until $\mathrm{P} 7$ days even though mRNA expression level was reduced between E15.5 and P7 days. mRNA expression levels were reduced back to early embryonic levels by P3 weeks. There was no significant difference between E12.5 days and P6 weeks or between E12.5 days and P75 weeks.

\section{Tropoelastin mRNA}

The mean mRNA level of tropoelastin (Fig. 8b) at E12.5 days was relatively low $(540.5 \pm 258.6)$. Significant elevations of tropoelastin mRNA expression levels were observed at E15.5 


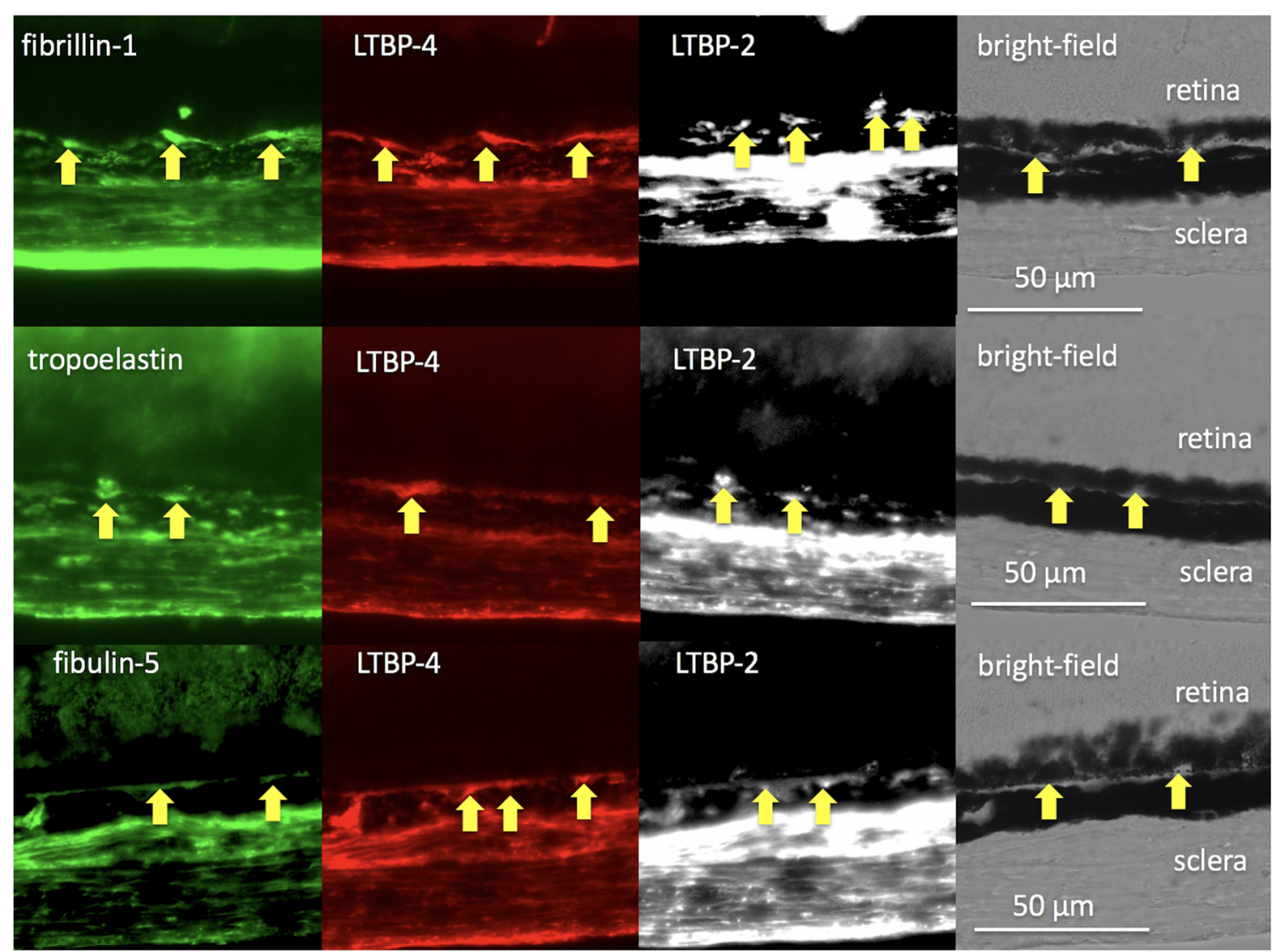

Fig. 3 Immunohistopathological findings in Bruch's membrane. Figure 3 is an image from a 6-week-old mouse. From postnatal stages and onwards, all proteins in Bruch's membrane clearly showed positive expression by staining. In each image, Bruch's membrane is shown as a yellow arrow. All images were taken at $\times 400$ magnification

\section{Fibulin-5 mRNA}

The mean mRNA level of fibulin-5 (Fig. 8c) were lowest at E12.5 days (150.8 \pm 68.6$)$. At E15.5 days, mRNA levels were elevated $(2635.7 \pm 689.1)$ and at their highest compared with those of other time points $(P<0.01)$. Fibulin-5 mRNA levels were significantly reduced at E18.5 days compared with E15.5 days $(P<0.01)$ and were maintained at high values
Fig. 4 Summary of

immunohistochemistry results in Bruch's membrane from each age group. The five proteins were found to be expressed in Bruch's membrane by

immunohistochemistry in postnatal mice; “+” positive staining, "-" negative staining, " \pm " between negative and positive

\begin{tabular}{|c|c|c|c|c|c|}
\hline & fibrillin-1 & tropoelastin & fibulin-5 & LTBP-2 & LTBP-4 \\
\hline E12.5 days & - & - & - & - & - \\
\hline E15.5 days & - & - & - & - & - \\
\hline E18.5 days & \pm & - & - & - & \pm \\
\hline P1 day & + & + & + & + & + \\
\hline P4 days & + & + & + & + & + \\
\hline P7 days & + & + & + & + & + \\
\hline P3 weeks & + & + & + & + & + \\
\hline P6 weeks & + & + & + & + & + \\
\hline P75 weeks & + & + & + & + & + \\
\hline
\end{tabular}




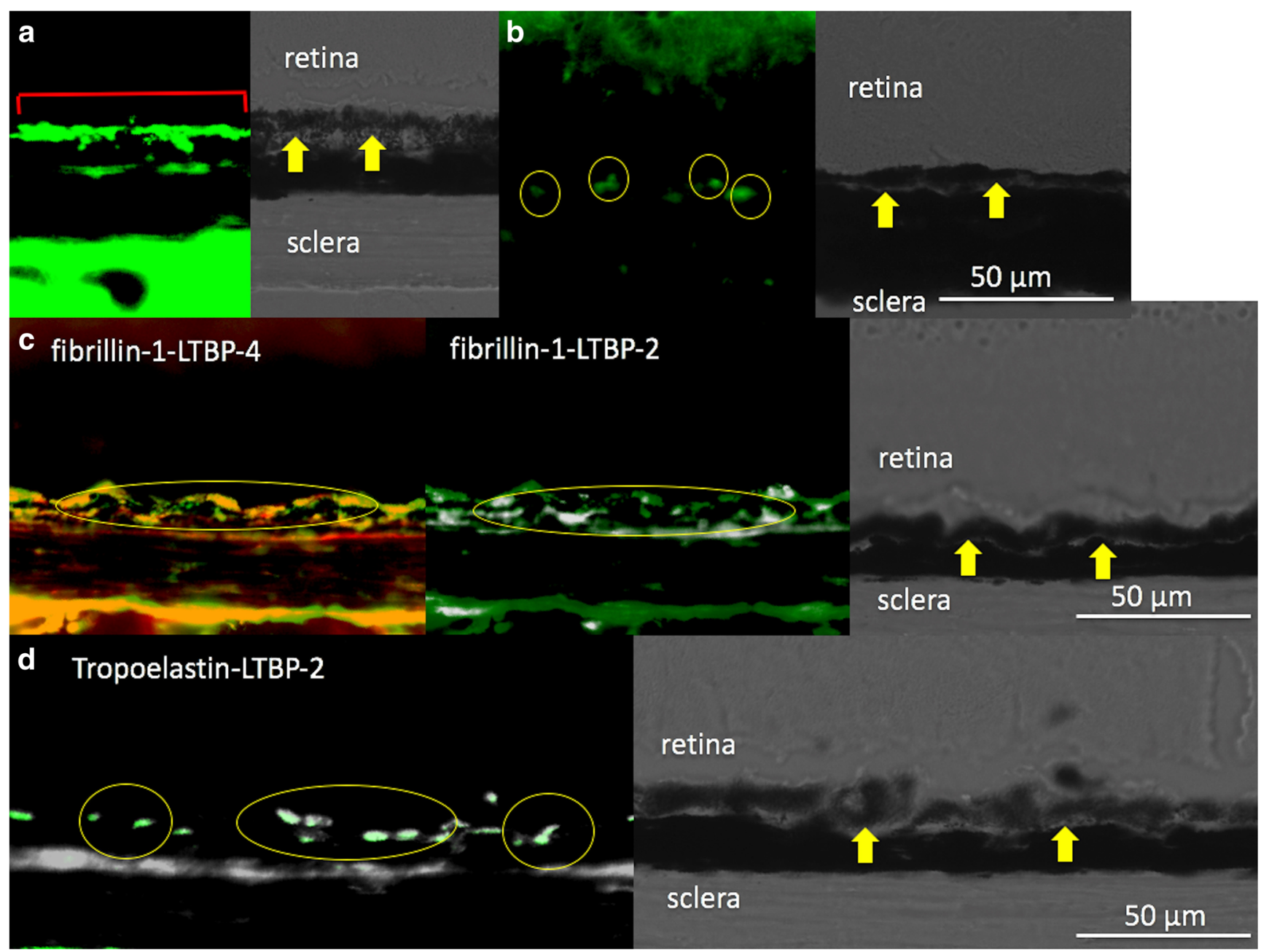

Fig. 5 Patterns of protein expression in Bruch's membrane. a Fibrillin-1, b tropoelastin, c fibrillin-1, and LTBP-2 (left image) and fibrillin-1 and LTBP-2 (middle image); $\mathbf{d}$ tropoelastin and LTBP-2. Fibrillin-1 proteins show relatively long, linear staining (red bracket). Tropoelastin proteins show dot-like staining (yellow, round). Co-localization of fibrillin-1 and
LTBP-2, fibrillin-1 and LTBP-2, and tropoelastin and LTBP-2 is observed. LTBP-2 and LTBP-4 staining overlaps with fibrillin-1. Tropoelastin and LTBP-2 punctate staining overlapped. All images were taken at $\times 400$ magnification

\section{LTBP-4 mRNA}

The mean mRNA (Fig. 8e) level at E12.5 days was lowest $(136.1 \pm 41.7)$ compared with those of other time points $(P<0.01)$. Elevations of mRNA levels were observed at E15.5 days (1433.4 \pm 707.8$)$. By E15.5 days, mRNA levels plateaued.

\section{Discussion}

The number of AMD patients is increasing for many reasons such as change of lifestyle (e.g., a western diet), an increase in the senior population, and genetic factors [51-55]. Clinically, AMD is divided into three types: typical AMD, PCV, and retinal angiomatous proliferation (RAP) [51-55]. Moreover, the development of CNV in AMD is divided into two types [52]: mRNA expression levels plateaued. 

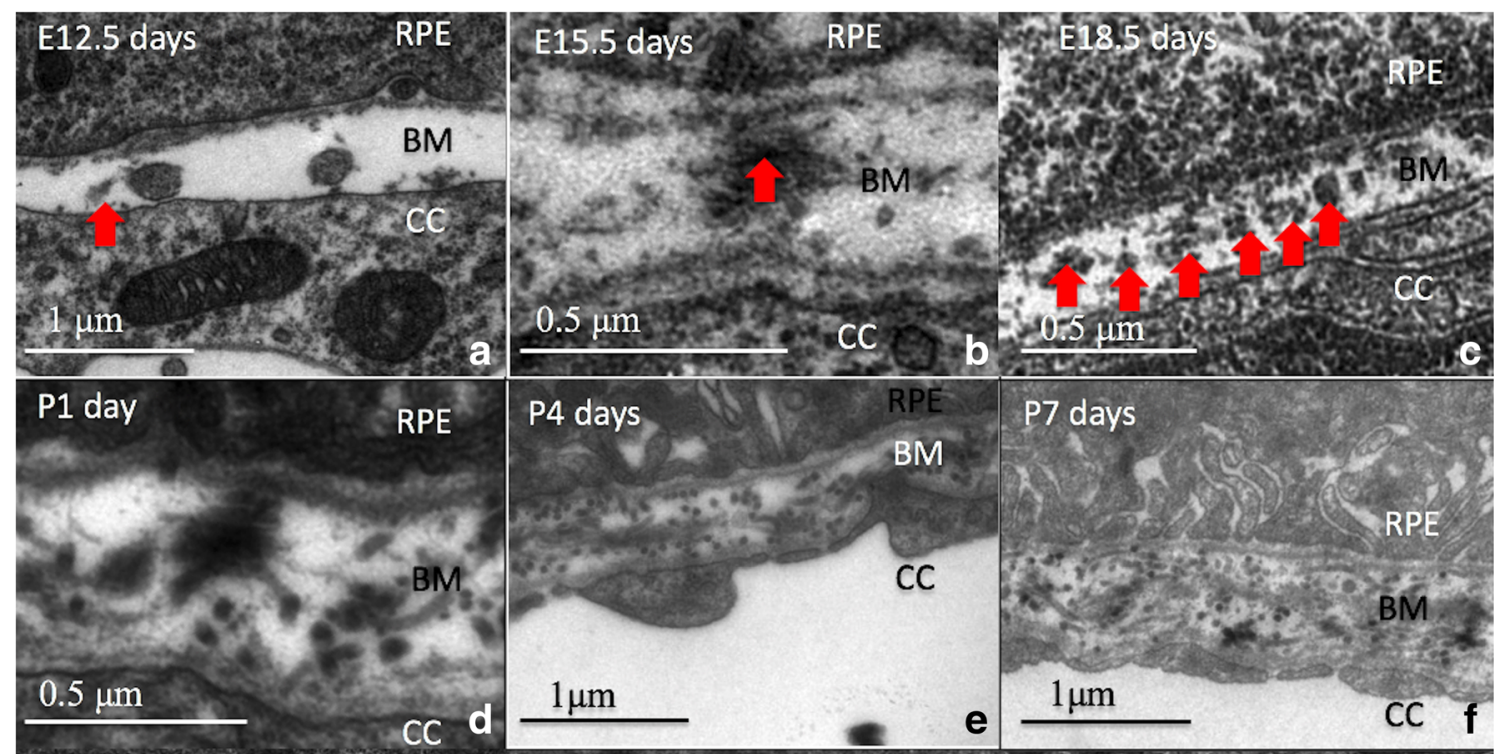

P7 days
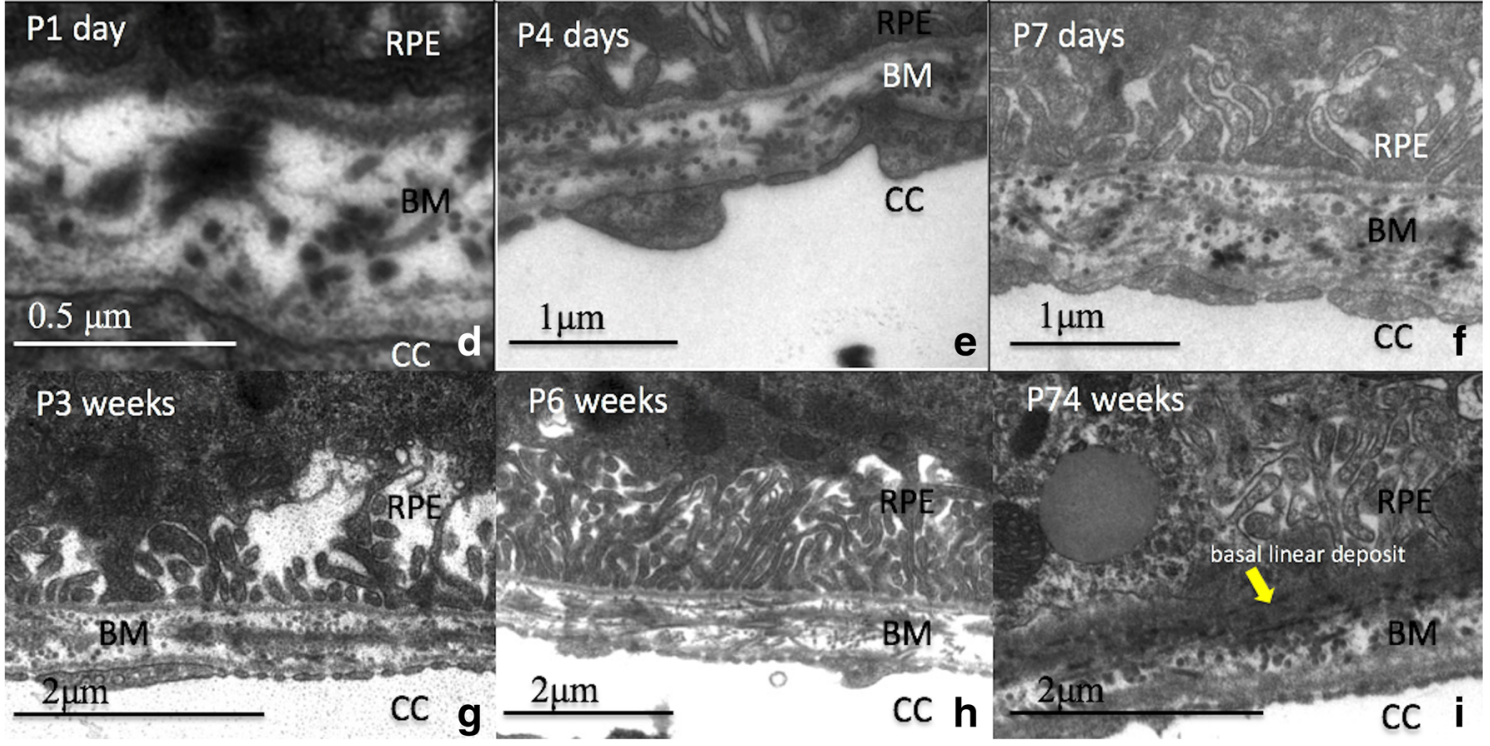

Fig. 6 Ultrastructural pre- and postnatal changes of Bruch's membrane in wild-type mice. Transmission electron micrographs of the elastic lamina of Bruch's membrane at embryonic 12.5 days (a), 15.5 days (b), 18.5 days (c), P1 day (d), P4 days (e), P7 days (f), P3 weeks (g), P6 weeks (h), and P74 weeks (i). Tropoelastin is stained as black dots by tannic acid and $p$ nitrophenol. A microfibril/tropoelastin (red arrow) complex appeared at embryonic early stage (a), increased in expression in the embryonic middle stage (b), and formed connections with one other by the embryonic

late stage (c, d). Extended microfibrils grew longer and thicker between P4 days and P3 weeks (e-g). Mature structure of the elastic lamina of Bruch's membrane revealed relatively continuous and thick fibers by $\mathrm{P} 3$ to 6 weeks (f, g). At P74 weeks (i), basal linear deposits prevented a clear elastic layer from being detected. Magnification-a $\times 28,700, \mathbf{b} \times$ $90,400, \mathbf{c} \times 59,200, \mathbf{d} \times 74,800, \mathbf{e} \times 28,700, \mathbf{f} \times 28,700, \mathbf{g} \times 21,400, \mathbf{h} \times$ 14,200 , and $\mathbf{i} \times 221,400$

type $1 \mathrm{CNV}$ arises from choroid to reach the sub-RPE space, and type $2 \mathrm{CNV}$ arises from choroid to reach the sub-retinal space. Typical AMD has type 1 and/or type $2 \mathrm{CNV}$ separately $[51,52]$. PCV has only type $1 \mathrm{CNV}$ [53]. RAP has types 1 and 2 CNVs in addition to chorioretinal anastomosis [55]. Among the three subtypes of AMD, the number of PCV patients in Asia is larger than that in Western countries [51, 53]. PCV can cause severe visual loss due to massive hemorrhage in the eye by ruptured polypoid lesions [54]. There have been many reports about animal models of CNVs $[8-15,56]$. Laser and surgically induced CNVs by penetrating BM have been widely used as experimental CNV models [8-11]. Recently, transgenic animal models have also been used for the investigation of CNVs [12-14]. Most of CNVs in these animal models belong to type 2 [8-14]. Conversely, only a few animal models of type $1 \mathrm{CNV}$ have been produced $[15,56]$. Moreover, there has been only 1 report about an animal model of PCV by Jones et al. This study found that the degeneration of the elastic lamina of BM is a fundamental factor for the occurrence of PCV [15]. There have

been many reports characterizing the elastic lamina of $\mathrm{BM}$; however, most previous reports assessed BM by only histological evaluation. There have been no reports about the relationship between essential molecules (fibrillin-1, tropoelatin, fibulin-5, LTBP-2 and LTBP-4) for elastic fiber assembly in the elastic lamina of BM. In this study, we found that fibrillin1, tropoelastin, fibulin-5, LTBP-2 and LTBP-4 proteins were expressed constitutively in $\mathrm{BM}$ at all postnatal stages by immunohistochemistry.

Fibrillins account for the majority of the microfibril complex [22-28]. Fibrillin monomers are long flexible molecules [24] encoded by three kinds of genes (fibrillin-1, fibrillin-2 and fibrillin-3) [27-29]. Each fibrillin-1 and fibrillin-2 plays a role in elastic fiber assembly. Fibrillin-1 and fibrillin-2 double knockout mice showed hypoplasia of elastic fibers, and mice deficient of either fibrillin gene resulted in elastogenesis $[28,31]$. The molecular organization of fibrillin-1 and fibrillin-2 is unclear. They have been found in the cornea [32], crystalline lens [33] and ciliary zonule [34, 35]. 
Fig. 7 Maturation of the elastic lamina of Bruch's membrane at postnatal week 6 . Transmission electron microscopy findings in Bruch's membrane of C57/BL mice at P6 weeks showed a relatively continuous elastic layer, with small gaps between long microfibrils (yellow asterisks). RPE, retinal pigment epithelium; BM, Bruch's membrane; $\mathrm{CC}$, choriocapillaris. Magnification, $\times 7140$

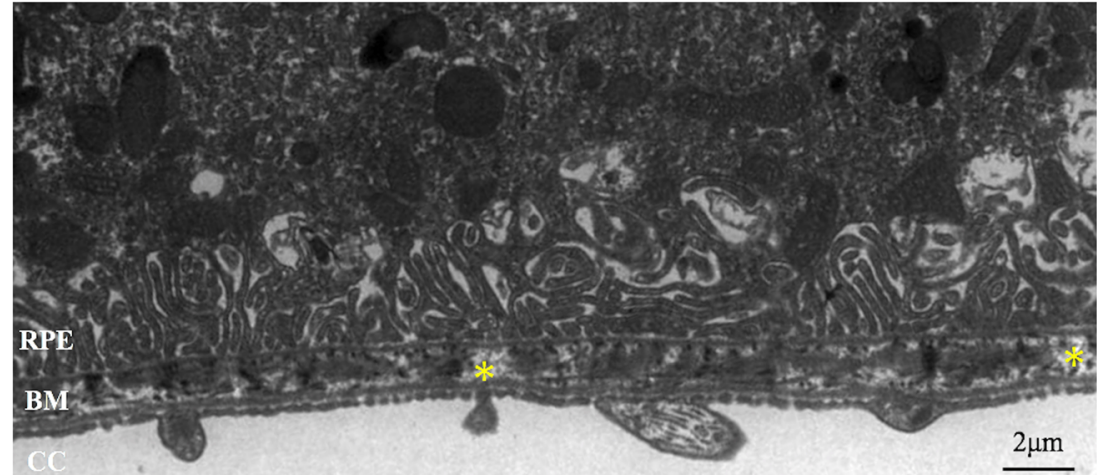

Mutations in the fibrillin-1 gene cause Marfan syndrome, which is associated with ectopia lentis [35]. Whether fibrillin-3 is involved in elastic fiber assembly or not remains unknown [29]. Within the three isoforms of the fibrillin family, fibrillin-1 is mainly responsible for forming microfibrils [25]. Thus, we studied fibrillin-1. Fibrillin microfibrils were first described as small-diameter fibrils located close to the basement membranes and also at the periphery of elastic fibers under the electron microscope [23]. In this study, fibrilllin-1rich microfibrils were seen as long bundles in BM at all postnatal stages under TEM. This result corresponded with the appearance in immunohistochemistry, which indicated that fibrillin-1 protein presents as a long linear pattern in BM at all postnatal stages.

Tropoelastin is the major component of elastic fiber, and fibrillin-1 forms microfibrils that act as a scaffold for tropoelastin. Tropoelastin presents as the non-cross-linked soluble precursor of elastin at less than $20^{\circ} \mathrm{C}$. Tropoelastin represents two stages in elastic fiber assembly; coacervation and cross-linking. The aqueous solutions aggregate at $37^{\circ} \mathrm{C}$ by interactions between hydrophobic domains. This process termed coacervation is reversible and thermodynamically controlled. The coacervate becomes steady and insoluble by cross-linking via lysyl oxidase (LOX)-like enzyme in an irreversible manner. LOX-like enzyme aligns tropoelastin molecules prior to cross-linking [19, 36, 37]. Thus, the microaggregation of tropoelastin deposited onto microfibrils and the cross-linked structure of tropoelastin by LOX-like enzyme are the major processes that form mature elastic fibers. In this study, the microaggregation of tropoelastin was observed as aggregation of black dots on the microfibril bundle using tannic acid and $p$-nitrophenol under TEM. This result corresponded with the appearance of tropoelastin in immunohistochemistry as well, in which tropoelastin protein stained as a dot-like pattern.

LTBPs are also integral components in elastic fiber assembly. There are four isoforms within the LTBP family (LTBP-1, LTBP-2, LTBP-3, and LTBP-4). The LTBP family regulates transforming growth factor- $\beta$ (TGF- $\beta$ ) bioavailability by binding and sequestering TGF- $\beta$ [42]. Among the four isoforms of the LTBP family, LTBP-1 and LTBP-3 are not required for the elastic fiber assembly reported by studies on mice and humans that are deficient in these genes [43]. LTBP-2, however, does not bind to TGF- $\beta$ [44]. Mutations in LTBP2 occur in ocular diseases including primary or secondary glaucoma, megalocornea, microspherophakia and ectopia lentis [45-47]. LTBP-2 facilitates the formation of thick microfibrils by binding fibrillin microfibrils into bundles in ciliary zonules [34].

In the absence of LTBP-4, the elastin/fibulin-5 complex is unable to linearly deposit on microfibrils, and misplaced aggregation of elastin/fibulin-5 forms globular structures [48]. In previous reports, interactions between fibrillin-1 and LTBP-2 or LTBP-4 indicated that LTBP-2 and LTBP-4 play a role in formation and maturation of microfibrils [34, 38]. In this study, we confirmed interaction between fibrillin-1 and LTBP-2 or LTBP-4 by localization in immunohistochemistry in BM. Moreover, we found a novel co-localization of LTBP2 and tropoelastin. We could not confirm co-localization of fibulin-5 and tropoelastin or LTBP-4 by immunohistochemistry. Unfortunately, we did not have evidence for how LTBP-2 and tropoelastin interact with each other in BM.

LTBP-4 localized on microfibril bundles is essential for linear assembly of elastin through interaction with fibulin-5 [48]. LTBP-4 and fibulin-5 play a role in proper accumulation of tropoelastin to the microfibril scaffold [48]. Nakamura et al. reported that the elastic fiber assembly process requires fibulin-5 using fibulin-5-deficient mice. These knockout mice resulted in loose skin, tortuous vessels, and emphysematous lungs [38, 39]. Yanagisawa reported that fibulin-5 can strongly interact with tropoelastin [40]. Hirai reported that fibulin-5 not only binds with tropoelastin but also promotes coacervation of tropoelastin in cell culture [41]. In human donor eyes, the fibulin-5 protein was localized in BM using immunohistochemistry [57]. In this study, fibulin-5 protein was expressed in BM in postnatal mice similar to human BM.

We have shown that the elastic fibers in BM were divided into microfibrils and tropoelastin separately using TEM. Our 

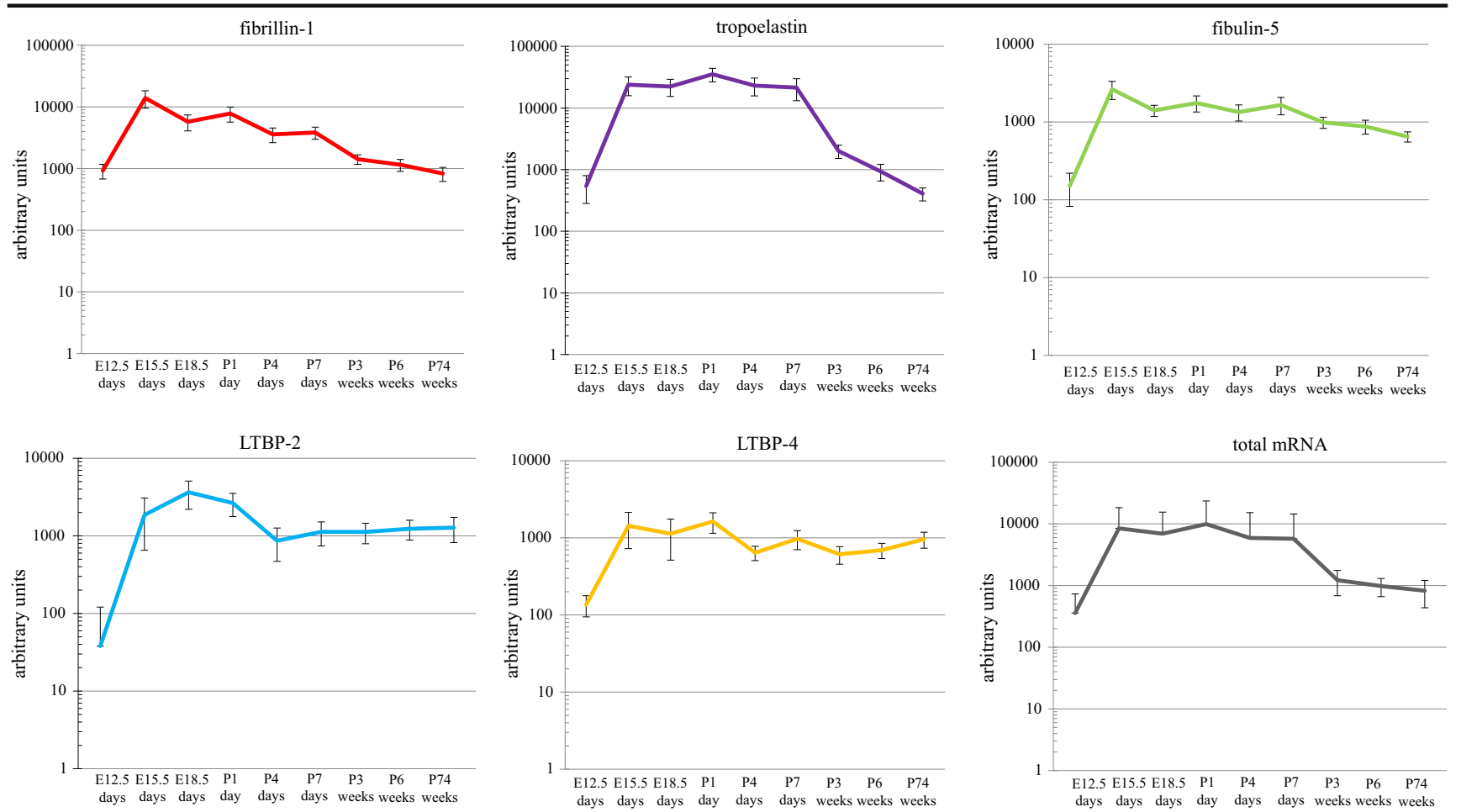

Fig. 8 mRNA abundance of each elastic fiber assembly-related protein in whole eye tissue. mRNA levels of fibrillin-1 (a), tropoelastin (b), fibulin5 (c), LTBP-2 (d), LTBP-4 (e), and total mRNA (f) were evaluated at preand postnatal stages with quantitative real-time PCR. Total mRNA expression levels were upregulated before and after birth. From postnatal

weeks 3 to 6 , mRNA expression plateaued at low levels, which indicates that production of each protein is finished in adult mice. The bars represent mean \pm SD. Statistics were analyzed by Tukey-Kramer $(n=16$ mice/group, $P<0.05$ )

TEM showed that there were slightly negligible clusters of microfibrils in the hollow space of BM at the embryonic early stage, which was consistent with the negative staining in immunohistochemistry and low level of each mRNA in qRTPCR at this same stage. TEM indicated that microfibril expression levels began to increase and tropoelastin began to deposit onto the cluster of microfibrils in the embryonic middle stage, which was consistent with the results of qRT-PCR. The expression levels of these five molecules (fibrillin-1, tropoelastin, fibulin-5, LTBP-2, and LTBP-4) were elevated in the embryonic middle stage.

Connections of each microfibril by tropoelastin between embryonic to postnatal stages allowed the elastic lamina of BM to gradually become mature fibers as shown under TEM. This TEM result coincides with immunohistochemistry, which shows positive staining of the five proteins by postnatal stages in immunohistochemistry.

Hirabayashi et al. defined the completion of the development of the elastic lamina of BM in normal mice as P6 weeks by the continuity of elastic fibers using TEM [2]. However, the elastic lamina of BM does not have full continuity from embryo to senile stages. In this study, we showed the maturation of the elastic lamina of BM using qualitative (TEM and immunohistochemistry) and quantitative (qRT-PCR) examinations. Relatively thick and continuous microfibrils with tropoelastin were observed from P3 to P6 weeks under TEM. Immunohistochemistry of all five proteins showed positive staining starting at postnatal stages. The mRNA levels of fibrillin-1, tropoelastin, and fibulin-5 remained high until P7 days and decreased by P3 weeks as shown by qRT-PCR. The mRNA levels of LTBP-2 and LTBP-4 remained high until P4 days and decreased by P7 days as shown by qRT-PCR. We also found that mRNA levels of the five proteins involved in elastic fiber assembly decreased starting at either P7 days or P3 weeks. According to the results of TEM, immunohistochemistry, and qRT-PCR, we define the maturation of elastic lamina of $\mathrm{BM}$ at $\mathrm{P} 3$ to $\mathrm{P} 6$ weeks.

With age, BM loses normal function and leads to degenerative changes [6, 58-65]. Discontinuities of elastic fiber of BM were observed in senescence accelerated mice (SAM), aging mice, and elderly people according to numerous studies [6, 16-23]. Increased length of discontinuities of the elastic lamina of BM may be the predilection for the occurrence of CNVs [6]. Furthermore, lipid deposits and other debris which are likely to play a role in the pathogenesis of AMD accumulated in BM in aging eyes [66, 67]. In this study, we showed abundant dense deposits in BM of senile mice (P75 weeks). These deposits aligned sub-RPE and BM in a similar manner to the basal linear deposits of human AMD. It was difficult to detect the elastic lamina of BM clearly in senile mice because 
of the abundant dense deposits located between the basement membrane of the RPE and the elastic lamina. Stone et al. hypothesized that fibulin-5 may be involved in basal deposit formation from the result that human patients with AMD have missense mutations in fibulin-5 [60]. The mechanism of how fibulin-5 mutations are related with AMD is not understood completely and must be addressed.

There are some limitations of this study. Further studies are needed to elucidate the elastic fiber assembly, age-related changes, and the formation of deposits in $\mathrm{BM}$ in the context of these five molecules. In this study, mRNA expression levels by qRT-PCR were measured from the whole eye. The eye itself contains various elastic fiber tissues such as the sclera, ciliary zonules, and BM. To strictly examine mRNA levels of the elastic lamina of BM, we would need to perform qRT-PCR using laser capture microdissection microscopy. Instead, we qualitatively assessed our proteins by using immunohistochemistry. To compare the quantitative protein expression levels, using Western blot or ELISA is recommended. In this study, we performed qRT-PCR on total ocular tissue because to collect proteins from such a small tissue as Bruch's membrane would yield a level of protein that is too small for analysis. In the future, we will have to study how each molecule interacts by using an immunoelectron microscope to fully understand how these proteins are assembled. Further studies including fibrillin-1, tropoelastin, fibulin-5, LTBP-2, and LTBP-4 transgenic mice may lead to understanding the elastic fiber formation in BM, which furthermore may lead to understanding the pathology of types 1 and 2 CNVs.

In summary, we studied immunohistochemical localization, ultrastructural changes, and mRNA levels of five proteins (fibrillin-1, tropoelastin, fibulin-5, LTBP-2, and LTBP4 ) in the EL of BM. We conclude that the EL became mature from P3 to P6 weeks as formerly stated. The structure of EL remained discontinuous throughout the age groups. Elastic fibers are still poorly understood, particularly in the BM, because they are complex and difficult to illustrate. Degradation of elastic fibers in BM may cause age-related disease such as AMD. Future therapeutic interventions which regenerate elastic fibers may be used instead of, or alongside, intravitreal anti-vascular endothelial growth factor (VEGF), and/or placental growth factor (PlGF) for the treatment of CNV.

Acknowledgements The authors thank Dr. Tomoya Akama and Dr. Tomoyuki Nakamura (Department of Pharmacology, Kansai Medical University, Osaka, Japan) for helpful discussion and for the gift of antibodies against fibrillin-1 and LTBP-2.

Author contributions Research design was performed by Hidetsugu Mori, Keiko Toyama, Tomoya Akama, Tadashi Inoue, and Tomoyuki Nakamura. Assays were performed by Hidetsugu Mori and Keiko
Toyama. Data analysis was performed by Hidetsugu Mori. Hidetsugu Mori wrote the paper with support of Haruhiko Yamada, Kanji Takahashi, Tomoya Akama, and Tomoyuki Nakamura.

Funding information None.

\section{Compliance with ethical standards}

All animal experiments were carried out in accordance with the ARVO Statement for the Use of Animals in Ophthalmic and Vision Research and the Guideline for Animal Experimentation at Kansai Medical University.

Conflict of interest The authors declare that they have no conflict of interest.

Abbreviations LTBP, Latent transforming growth factor beta-binding protein; EL, Elastic lamina; BM, Bruch's membrane; IH, Immunohistochemical staining; TEM, Transmission electron microscopy; qRT-PCR, Quantitative real-time PCR; RPE, Retinal pigment epithelium; CCE, Choriocapillaris endothelium; CNV, Choroidal neovascularization; AMD, Age-related macular degeneration; HTRA1, Human hightemperature requirement A 1; PCV, Polypoidal choroidal vasculopathy; PBS, Phosphate-buffered saline; LOX, Lysyl oxidase; TGF- $\beta$, Transforming growth factor- $\beta$; VEGF, Vascular endothelial growth factor; PIGF, Placental growth factor

Open Access This article is distributed under the terms of the Creative Commons Attribution 4.0 International License (http:// creativecommons.org/licenses/by/4.0/), which permits unrestricted use, distribution, and reproduction in any medium, provided you give appropriate credit to the original author(s) and the source, provide a link to the Creative Commons license, and indicate if changes were made.

\section{References}

1. Das A, Frank RN, Zhang NL, Turczyn TJ (1990) Ultrastructural localization of extracellular matrix components in human retinal vessels and Bruch's membrane. Arch Ophthalmol 108:421-429

2. Hirabayashi Y, Fujimori O, Shimizu S (2003) Bruch's membrane of the brachymorphic mouse. Med Electron Microsc 36:139-146. https://doi.org/10.1007/s00795-003-0218-z

3. Booij JC, Baas DC, Beisekeeva J, Gorgels TG, Bergen AA (2010) The dynamic nature of Bruch's membrane. Prog Retin Eye Res 29: 1-18. https://doi.org/10.1016/j.preteyeres.2009.08.003

4. Guymer R, Luthert P, Bird A (1990) Changes in Bruch's membrane and related structures with age. Prog Retin Eye Res 18:59-90

5. Kresse H, Schönherr E (2001) Proteoglycans of the extracellular matrix and growth control. J Cell Physiol 189:266-274. https://doi. org/10.1002/jcp. 10030

6. Chong NH, Keonin J, Luthert PJ, Frennesson CI, Weingeist DM, Wolf RL et al (2005) Decreased thickness and integrity of the macular elastic layer of Bruch's membrane correspond to the distribution of lesions associated with age-related macular degeneration. Am J Pathol 166:241-251. https://doi.org/10.1016/S00029440(10)62248-1

7. Goldberg MF (1976) Bruch's membrane and vascular growth. Investig Ophthalmol 15:443-446

8. Tobe T, Ortega S, Luna JD, Ozaki H, Okamoto N, Derevjanik NL et al (1998) Targeted disruption of the FGF2 gene does not prevent choroidal neovascularization in a murine model. Am J Pathol 153: 1641-1646. https://doi.org/10.1016/S0002-9440(10)65753-7 
9. Ryan SJ (1979) The development of an experimental model of subretinal neovascularization in disciform macular degeneration. Trans Am Ophthalmol Soc 77:707-745

10. Sakamoto T, Sanui H, Ishibashi T, Kohno T, Takahira K, Inomata H et al (1994) Subretinal neovascularization in the rat induced by IRBP synthetic peptides. Exp Eye Res 58:155-160

11. Spilsbury K, Garrett KL, Shen WY, Constable IJ, Rakoczy PE (2000) Overexpression of vascular endothelial growth factor (VEGF) in the retinal pigment epithelium leads to the development of choroidal neovascularization. Am J Pathol 2000 157:135-144. Erratum in: Am J Pathol;157:1413. https://doi.org/10.1016/S00029440(10)64525-7

12. Elizabeth Rakoczy P, Yu MJ, Nusinowitz S, Chang B, Heckenlively JR (2006) Mouse models of age-related macular degeneration. Exp Eye Res 82:741-752. https://doi.org/10.1016/j.exer.2005.10.012

13. Ambati J, Anand A, Fernandez S, Sakurai E, Lynn BC, Kuziel WA et al (2003) An animal model of age-related macular degeneration in senescent Ccl-2- or Ccr-2-deficient mice. Nat Med 9:1390-1397. https://doi.org/10.1038/nm950

14. Dithmar S, Curcio CA, Le NA, Brown S, Grossniklaus HE (2000) Ultrastructural changes in Bruch's membrane of apolipoprotein Edeficient mice. Invest Ophthalmol Vis Sci 41:2035-2042

15. Jones A, Kumar S, Zhang N, Tong Z, Yang JH, Watt C et al (2011) Increased expression of multifunctional serine protease, HTRA1, in retinal pigment epithelium induces polypoidal choroidal vasculopathy in mice. Proc Natl Acad Sci U S A 108:14578-14583. https:// doi.org/10.1073/pnas.1102853108

16. Sivaprasad S, Chong NV, Bailey TA (2005) Serum elastin-derived peptides in age-related macular degeneration. Invest Ophthalmol Vis Sci 46:3046-3051. https://doi.org/10.1167/iovs.04-1277

17. Nie GY, Hampton A, Li Y, Findlay JK, Salamonsen LA (2003) Identification and cloning of two isoforms of human hightemperature requirement factor $\mathrm{A} 3$ ( $\mathrm{Htr} \mathrm{A} 3)$, characterization of its genomic structure and comparison of its tissue distribution with HtrA1 and HtrA2. Biochem J 371:39-48. https://doi.org/10.1042/ BJ20021569

18. Zurawa-Janicka D, Skorko-Glonek J, Lipinska B (2010) HtrA proteins as targets in therapy of cancer and other diseases. Expert Opin Ther Targets 14:665-679. https://doi.org/10.1517/14728222.2010. 487867

19. Vrhovski B, Weiss AS (1998) Biochemistry of tropoelastin. Eur J Biochem 258:1-18

20. Rosenbloom J, Abrams WR, Mecham R (1993) Extracellular matrix 4: the elastic fiber. FASEB J 7:1208-1218

21. Kielty CM, Sherratt MJ, Shuttleworth CA (2002) Elastic fibres. J Cell Sci 115:2817-2828

22. Ramirez F, Sakai LY, Dietz HC, Rifkin DB (2004) Fibrillin microfibrils, multipurpose extracellular networks in organismal physiology. Physiol Genomics 19:151-154

23. Low FN (1962) Microfibrils: fine filamentous components of the tissue space. Anat Rec 142:131-137

24. Sakai LY, Keene DR, Glanville RW, Bächinger HP (1991) Purification and partial characterization of fibrillin, a cysteine-rich structural component of connective tissue microfibrils. J Biol Chem 266:14763-14770

25. Sakai LY, Keene DR, Engvall E (1986) Fibrillin, a new 350-kD glycoprotein, is a component of extracellular microfibrils. J Cell Biol 103:2499-24509

26. Jensen SA, Reinhardt DP, Gibson MA, Weiss AS (2001) Protein interaction studies of MAGP-1 with tropoelastin and fibrillin-1. J Biol Chem 276:39661-39666. https://doi.org/10.1074/jbc. M104533200

27. Zhang H, Apfelroth SD, Hu W, Davis EC, Sanguineti C, Bonadio J et al (1994) Structure and expression of fibrillin-2, a novel microfibrillar component preferentially located in elastic matrices. J Cell Biol 124:855-863
28. Pereira L, D’Alessio M, Ramirez F, Lynch JR, Sykes B, Pangilinan $T$ et al (1993) Genomic organization of the sequence coding for fibrillin, the defective gene product in Marfan syndrome. Hum Mol Genet 2:1762

29. Nagase T, Nakayama M, Nakajima D, Kikuno R, Ohara O (2001) Prediction of the coding sequences of unidentified human genes. $\mathrm{XX}$. The complete sequences of 100 new cDNA clones from brain which code for large proteins in vitro. DNA Res 8:85-95

30. Mariencheck MC, Davis EC, Zhang H, Ramirez F, Rosenbloom J, Gibson MA et al (1995) Fibrillin-1 and fibrillin-2 show temporal and tissue-specific regulation of expression in developing elastic tissues. Connect Tissue Res 31:87-97

31. Carta L, Pereira L, Arteaga-Solis E, Lee-Arteaga SY, Lenart B, Starcher B et al (2006) Fibrillins 1 and 2 perform partially overlapping functions during aortic development. J Biol Chem 281:80168023. https://doi.org/10.1074/jbc.M511599200

32. Resch MD, Schlötzer-Schrehardt U, Hofmann-Rummelt C, Kruse FE, Seitz B (2009) Alterations of epithelial adhesion molecules and basement membrane components in lattice corneal dystrophy (LCD). Graefes Arch Clin Exp Ophthalmol 247:1081-1088. https://doi.org/10.1007/s00417-009-1046-1

33. Hubmacher D, Reinhardt DP, Plesec T, Schenke-Layland K, Apte SS (2014) Human eye development is characterized by coordinated expression of fibrillin isoforms. Invest Ophthalmol Vis Sci 55: 7934-7944. https://doi.org/10.1167/iovs.14-15453

34. Inoue T, Ohbayashi T, Fujikawa Y, Yoshida H, Akama TO, Noda K et al (2014) Latent TGF- $\beta$ binding protein- 2 is essential for the development of ciliary zonule microfibrils. Hum Mol Genet 23: 5672-5682. https://doi.org/10.1093/hmg/ddu283

35. Liu W, Qian C, Comeau K, Brenn T, Furthmayr H, Francke U (1996) Mutant fibrillin-1 monomers lacking EGF-like domains disrupt microfibril assembly and cause severe marfan syndrome. Hum Mol Genet 5:1581-1587

36. Vrhovski B, Jensen S, Weiss AS (1997) Coacervation characteristics of recombinant human tropoelastin. Eur J Biochem 250:92-98

37. Mithieux SM, Weiss AS (2005) Elastin. Adv Protein Chem 70: 437-461. https://doi.org/10.1016/S0065-3233(05)70013-9

38. Nakamura T, Lozano PR, Ikeda Y, Iwanaga Y, Hinek A, Minamisawa $S$ et al (2002) Fibulin-5/DANCE is essential for elastogenesis in vivo. Nature 415:171-175. https://doi.org/10. 1038/415171a

39. Nakamura T, Ruiz-Lozano P, Lindner V, Yabe D, Taniwaki M, Furukawa Y et al (1999) DANCE, a novel secreted RGD protein expressed in developing, atherosclerotic, and balloon-injured arteries. J Biol Chem 274:22476-22483

40. Yanagisawa H, Davis EC, Starcher BC, Ouchi T, Yanagisawa M, Richardson JA et al (2002) Fibulin-5 is an elastin-binding protein essential for elastic fibre development in vivo. Nature 415:168-171. https://doi.org/10.1038/415168a

41. Hirai M, Ohbayashi T, Horiguchi M, Okawa K, Hagiwara A, Chien KR, Kita T, Nakamura T (2007) Fibulin-5/DANCE has an elastogenic organizer activity that is abrogated by proteolytic cleavage in vivo. J Cell Biol 176:1061-1071. https://doi.org/10.1083/ jcb.200611026

42. Rifkin DB (2005) Latent transforming growth factor-beta (TGFbeta) binding proteins: orchestrators of TGF-beta availability. $\mathrm{J}$ Biol Chem 280:7409-7412. https://doi.org/10.1074/jbc. R400029200

43. Todorovic V, Rifkin DB (2012) LTBPs, more than just an escort service. J Invest Dermatol 132:448-457. https://doi.org/10.1002/ jcb. 23385

44. Saharinen J, Keski-Oja J (2000) Specific sequence motif of 8-Cys repeats of TGF-beta binding proteins, LTBPs, creates a hydrophobic interaction surface for binding of small latent TGF-beta. Mol Biol Cell 11:2691-2704 
45. Ali M, McKibbin M, Booth A, Parry DA, Jain P, Riazuddin SA et al (2009) Null mutations in LTBP2 cause primary congenital glaucoma. Am J Hum Genet 84:664-671. https://doi.org/10.1016/j.ajhg. 2009.03.017

46. Narooie-Nejad M, Paylakhi SH, Shojaee S, Fazlali Z, Rezaei Kanavi M, Nilforushan N et al (2009) Loss of function mutations in the gene encoding latent transforming growth factor beta binding protein 2, LTBP2, cause primary congenital glaucoma. Hum Mol Genet 18:3969-3977. https://doi.org/10.1093/hmg/ddp338

47. Azmanov DN, Dimitrova S, Florez L, Cherninkova S, Draganov D, Morar B et al (2011) LTBP2 and CYP1B1 mutations and associated ocular phenotypes in the Roma/gypsy founder population. Eur $\mathrm{J}$ Hum Genet 19:326-333. https://doi.org/10.1038/ejhg.2010.181

48. Noda K, Dabovic B, Takagi K, Inoue T, Horiguchi M, Hirai M et al (2013) Latent TGF- $\beta$ binding protein 4 promotes elastic fiber assembly by interacting with fibulin-5. Proc Natl Acad Sci U S A 110: 2852-2857. https://doi.org/10.1073/pnas.1215779110

49. Smith RS, John SWM, Nishina PM, Sundberg JP (2001) Systematic evaluation of the mouse eye: anatomy, pathology, and biomethods. CRC Press, Boca Raton, FL, pp 45-63

50. Kawamoto T, Kawamoto K (2014) Preparation of thin frozen sections from nonfixed and undecalcified hard tissues using Kawamot's film method (2012). Methods Mol Biol 130:149-164. https://doi.org/10.1007/978-1-62703-989-5 11

51. Yoshimura N (2016) Age-related macular degeneration. Nippon Ganka Gakkai Zasshi [in Japanese] 120:163-188

52. Ho AC, Yannuzzi LA, Pisicano K, DeRosa J (1995) The natural history of idiopathic subfoveal choroidal neovascularization. Ophthalmology 102:782-789

53. Imamura Y, Engelbert M, Iida T, Freund KB, Yannuzzi LA (2010) Polypoidal choroidal vasculopathy: a review. Surv Ophthalmol 55: 501-515. https://doi.org/10.1016/j.survophthal.2010.03.004

54. Jalali S, Parra SL, Majji AB, Hussain N, Shah V (2006) Ultrasonographic charac-teristics and treatment outcomes of surgery for vitreous hemorrhage in idiopathic polypoidal choroidal vasculopathy. Am J Ophthalmol 142:608-619. https://doi.org/10. 1016/j.ajo.2006.05.055

55. Yannuzzi LA, Negrão S, Iida T, Carvalho C, Rodriguez-Coleman $\mathrm{H}$, Slakter J et al (2012) Retinal angiomatous proliferation in agerelated macular degeneration. Retina 21:416-434

56. Nagai N, Lundh von Leithner P, Izumi-Nagai K, Hosking B, Chang B, Hurd R et al (2014) Spontaneous CNV in a novel mutant mouse is associated with early VEGF-A-driven angiogenesis and latestage focal edema, neural cell loss, and dysfunction. Invest
Ophthalmol Vis Sci 55:3709-3719. https://doi.org/10.1167/iovs. 14-13989

57. Mullins RF, Olvera MA, Clark AF, Stone EM (2007) Fibulin-5 distribution in human eyes: relevance to age-related macular degeneration. Exp Eye Res 84:378-380. https://doi.org/10.1016/j.exer. 2006.09.021

58. Hogan MJ, Alvarado J (1967) Studies on the human macula. IV. Aging changes in Bruch's membrane. Arch Ophthalmol 77:410 420

59. Sarks SH (1976) Ageing and degeneration in the macular region: a clinico-pathological study. Br J Ophthalmol 160:324-341

60. Green WR, McDonnell PJ, Yeo JH (1985) Pathologic features of senile macular degeneration. Ophthalmology 92:615-627

61. Grindle CF, Marshall J (1978) Ageing changes in Bruch's membrane and their functional implications. Trans Ophthalmol Soc U K 98:172-175

62. Feeney-Burns L, Ellersieck MR (1985) Age-related changes in the ultrastructure of Bruch's membrane. Am J Ophthalmol 100:686697

63. Ramrattan RS, van der Schaft TL, Mooy CM, de Bruijn WC, Mulder PG, de Jong PT (1994) Morphometric analysis of Bruch's membrane, the choriocapillaris, and the choroid in aging. Invest Ophthalmol Vis Sci 35:2857-2864

64. Spraul CW, Lang GE, Grossniklaus HE, Lang GK (1999) Histologic and morphometric analysis of the choroid, Bruch's membrane, and retinal pigment epithelium in postmortem eyes with age-related macular degeneration and histologic examination of surgically excised choroidal neovascular membranes. Surv Ophthalmol 44:S10-S32

65. Majji AB, Cao J, Chang KY, Hayashi A, Aggarwal S, Grebe RR et al (2000) Age-related retinal pigment epithelium and Bruch's membrane degeneration in senescence-accelerated mouse. Invest Ophthalmol Vis Sci 41:3936-3942

66. Schmidt-Erfurth U, Rudolf M, Funk M, Hofmann-Rummelt C, Franz-Haas NS, Aherrahrou Z et al (2008) Ultrastructural changes in a murine model of graded Bruch membrane lipoidal degeneration and corresponding VEGF164 detection. Invest Ophthalmol Vis Sci 49:390-398. https://doi.org/10.1167/IOVS.07-0227

67. Sato R, Yasukawa T, Kacza J, Eichler W, Nishiwaki A, Iandiev I et al (2013) Three-dimensional spheroidal culture visualization of membranogenesis of Bruch's membrane and basolateral functions of the retinal pigment epithelium. Invest Ophthalmol Vis Sci 54: 1740-1749. https://doi.org/10.1167/iovs.12-10068 